\title{
DISSECTING ANEURYSM OF THE AORTA IN TWO SISTERS
}

\author{
BY \\ C. W. LAWSON AND C. P. ALEXANDER \\ From the Royal Infirmary, Leicester, and the Royal Hospital, Sheffield
}

Dissecting aneurysm of the aorta extending from the arch to below the bifurcation is not uncommon but the following case is unusual for two reasons. Both the patient and her sister died in their third decade from hæmopericardium due to dissecting aneurysms, and in the case of the patient re-entry of the aneurysm had taken place into both common iliac arteries.

\section{Case Report}

A housewife, aged 30, went swimming one morning in July 1960 . The same afternoon she stood on a chair to reach something from a high shelf: with her arms stretched upwards she nearly over-balanced and, when righting herself, she experienced a sudden sharp terrifying pain in the back of her throat. The pain travelled downwards and when it reached the midsternal region she felt "as if something gave way" in her chest. At the same time the pain radiated to her back and both arms, and then moved further downwards through the epigastrium (where she had a feeling of warmth) into both legs. The pain was maximal at onset and in its very severe form lasted for about ten minutes in her chest, arms, and legs: it was then replaced by a severe aching soreness. She also had a headache. Her husband noted engorgement of her neck vessels at this stage. A doctor was summoned and when he came the soreness prevented the patient from lying down to be examined. She noted that when the doctor palpated her abdomen, wherever he pressed he caused her to have pain in the mid-epigastrium. She did not notice any cyanosis, mottling, or loss of power of her limbs, although her face was stated to be ashen.

The soreness in the epigastrium persisted for four days, diminishing gradually. On the second day she vomited several times and eventually brought up some streaks of bright red blood. At this time her blood pressure was noted to be $150 / 95$, the heart was thought to be slightly enlarged clinically, but no murmurs were heard.

She recovered from this attack but was left with a complaint of persistent tachycardia and palpitation, aggravated by effort. A cholecystogram showed a poorly functioning gall bladder with gallstones. An $\mathrm{X}$-ray of the chest showed some widening of the first part of the aorta (Fig. 1B). Films taken 6 years and 4 years previously (Fig. 1A) were subsequently obtained and showed a normal heart and aorta.

Because of the widening aorta she was referred to the Cardiac Clinic at the Leicester Chest Unit where she was seen in August. The past history was significant in that she had had toxæmia of pregnancy in her last two pregnancies, one in 1956 that resulted in a still birth, and one in 1958 when she was reported to have suffered a brief but severe collapse, without pain, but with sweating and a low blood pressure lasting a few hours, for which no cause could be found.

Her family history was interesting in that two relatives died suddenly. A maternal uncle dropped dead while ice skating at the age of 29 , and his death was vaguely stated as being due to his heart. One of her two sisters died suddenly at the age of 25 , five days after childbirth. The autopsy showed a hamopericardium due to rupture of a dissecting aneurysm. There were $360 \mathrm{ml}$. of blood clot in the pericardium and the heart size and weight were recorded as normal. There was no record of any other congenital or developmental abnormality present and none had been known to her relatives during life.

On examination she appeared well. There was slight sternal depression. Her pulse was 110 a minute and regular. Her blood pressure was $115 / 60 \mathrm{~mm}$. $\mathrm{Hg}$ in both arms. The heart was not enlarged clinically. A soft aortic diastolic murmur was present to the left of the sternum. There was no venous engorgement in the neck. The rest of the physical examination was normal. All peripheral pulses were palpable and appeared normal. There was duplication of the heart sounds over the major vessels of the left side of the neck, but not on the right. 


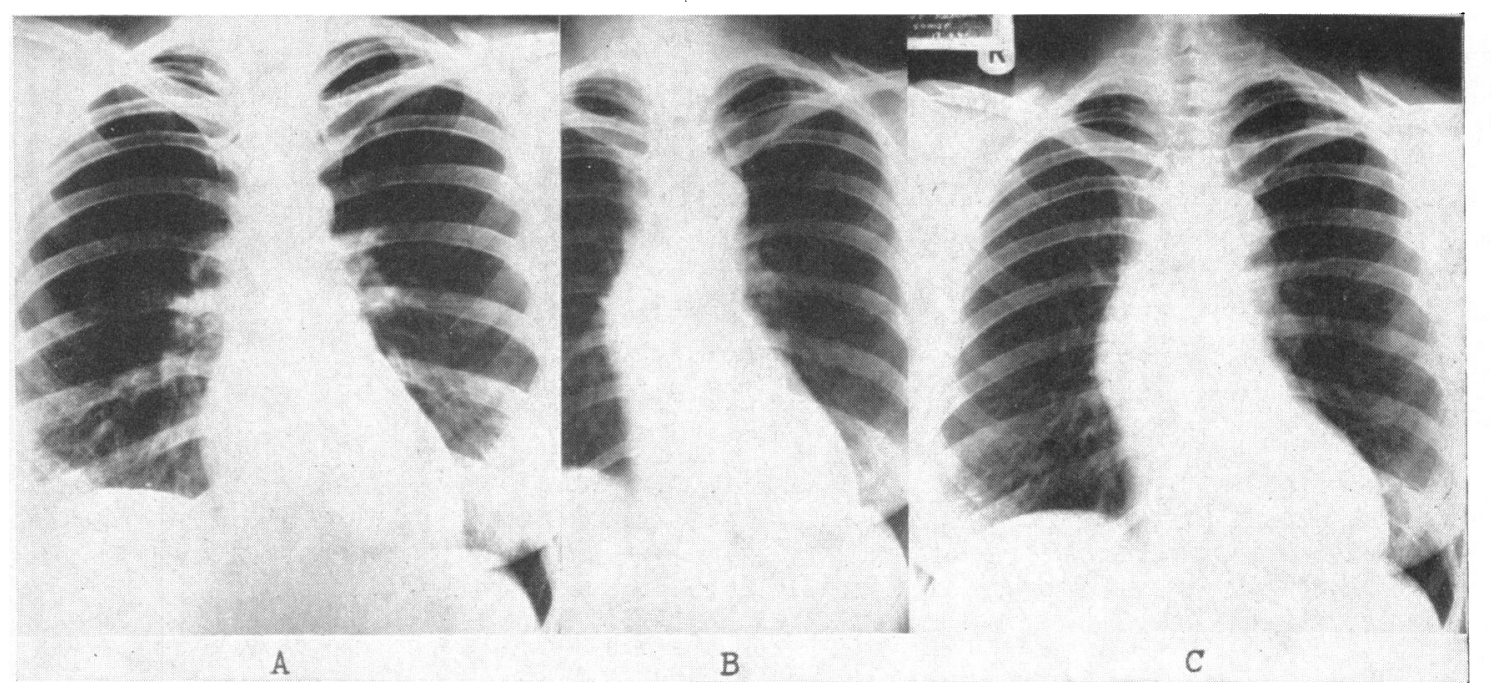

FIG. 1.-Teleradiograms of the heart. (A) Four years before. (B) August 1960, soon after her attack. (C) A month later.

Screening of the heart and X-ray of chest showed slight enlargement of the left ventricle. There was marked widening and pulsation of the ascending aorta and to a lesser extent of the arch of the aorta. The electrocardiogram showed sinus rhythm and was within normal limits. The urine was normal. The blood count was normal. E.S.R. $32 \mathrm{~mm} . / \mathrm{hr}$. Serum cholesterol $285 \mathrm{mg}$. per $100 \mathrm{ml}$. Wasserman reaction negative.

On this history and these findings a diagnosis of dissecting aneurysm of the aorta was made.

Progress. Two weeks later (11/9/60) she was admitted to hospital because of short bouts of breathlessness and a feeling of tightness in the root of the neck. She had two attacks lasting about five minutes, each with palpitation and followed by aching on the shoulders. The physical examination was essentially as before, with a regular pulse rate of 90 beats a minute. No abnormalities were detected in the major peripheral blood vessels. Chest X-ray showed further widening of the ascending aorta (Fig. 1C). Cardiogram, as before. Hæmoglobin, 80 per cent. W.B.C. 4700 per cu. mm. E.S.R. $4 \mathrm{~mm}$. in $1 \mathrm{hr}$. Van den Bergh reaction negative. Serum bilirubin less than $0.05 \mathrm{mg}$. per $100 \mathrm{ml}$. While in hospital she had two further short attacks of constriction in the throat and chest, during which the pulse rate rose to 120 a minute and the blood pressure to $180 / 100 \mathrm{~mm}$. $\mathrm{Hg}$. No further incidents occurred and she was allowed home a month later.

Second attack. While she was in bed, 24 days later, she experienced a sudden crushing chest pain, associated with sweating, collapse, breathlessness, and vomiting. The blood pressure then was not recordable, and she was semi-conscious. Six hours later, on admission to the Royal Hospital, Sheffield, s ie was shocked and pale, sweating and dyspnœic, with a blood pressure of $85 / 55 \mathrm{~mm}$. and a pulse rate of 120 a minute. There was an apical triple rhythm, with an aortic early diastolic murmur becoming more clearly heard in succeeding hours. Other findings and investigations as before.

She was making a gradual recovery until on the fourth day she cried out while using a bedpan, and collapsed and died within three minutes, showing engorged neck veins and an increase in the area of cardiac dullness. Heart sounds were absent before respiration ceased.

Necropsy. Heart and aorta. Blood in the pericardium, $500 \mathrm{ml}$., clotted. The ascending aorta showed a very recent tear $(2 \times 0.5 \mathrm{~cm}$.) $4 \mathrm{~cm}$. above the aortic valves. Healed ruptured intima from $2 \mathrm{~cm}$. to $5 \mathrm{~cm}$. above the aortic valves, upper edge curled up. Left carotid continuous with original aorta. A tube with colourless lining extending from the aortic arch to the common iliac arteries reopened into the original channels at the commencement of the left iliac artery and $3 \mathrm{~cm}$. into the right common iliac artery. Old thrombus at the apex of the blood channel on the left (abutting on the left common iliac artery). The ostium of the cœliac axis lay at the junction of the channels 


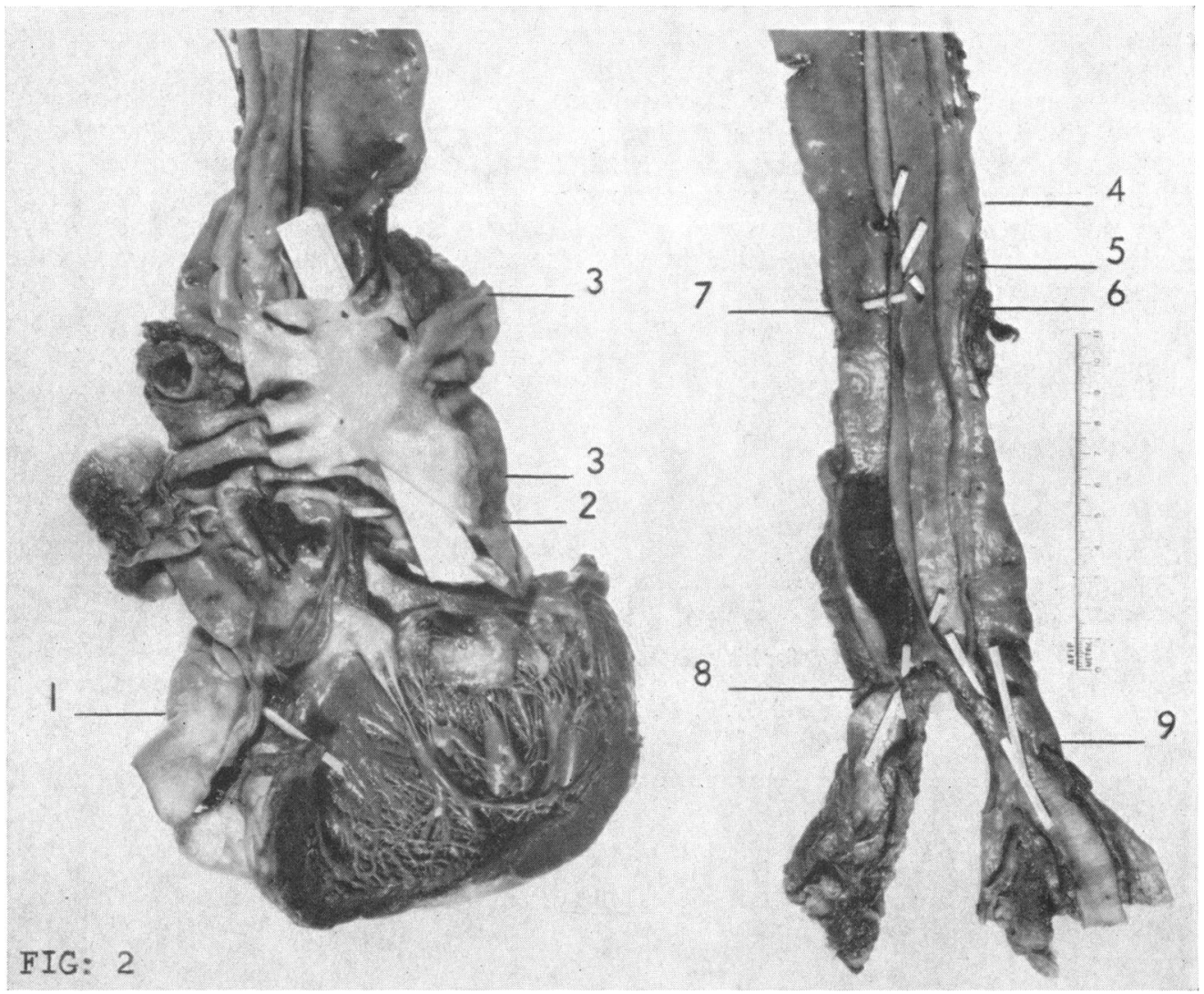

Fig. 2.-Photograph of necropsy specimen. Heart opened from in front and aorta from posterior aspect. (1) Probe in right coronary artery. (2) Probe in left coronary artery. (3) Probe passing from entry split in aortic arch, through false sac in arch. (4) Coliac axis. (5) Superior mesenteric artery. (6) Right renal artery. (7) Left renal artery. (8) Re-entry into left common iliac artery partially obstructed by blood clot. (9) Probe passing from false sac through re-entry into right common iliac artery.

but mainly in the new channel, the superior mesenteric artery being entirely in the original channel. The left renal artery communicated by a "window" with each channel (Fig. 2).

- Histological Changes. Substantial amounts of mucinous substance were seen in the unruptured part of the aorta. Flattened endothelial cells lined the new channel and deep to these were substantial amounts of mucinous substances.

The other viscera showed little of interest.

\section{Discussion}

This case emphasises the paramount importance of a good history in arriving at the diagnosis of dissecting aneurysm. The patient described the progress of the dissection clearly after the first attack, and had a history of toxæmia of pregnancy on two occasions.

One circumstance where one might expect dissecting aneurysms in a family would be in Marfan's syndrome, but clinically there were no features of the syndrome, and measurements of arm span and upper and lower segments were within normal limits. The metacarpal index estimated from an X-ray of the hand was $8 \cdot 3$, which according to Sinclair et al. (1960) is higher than the normal but 
below the Marfan range. There was no dislocation of the lens or other congenital abnormality, and no family history of Marfan syndrome. The patient's surviving sister is normal, and has a normal blood pressure.

In the history of her progress, the bouts of breathlessness were due to left ventricular failure, associated with the aortic regurgitation, while the attacks of tightness in the throat appeared to be due to expansion of the enlarged aorta associated with a rise of blood pressure and obstruction of the superior mediastinum. That they were not due to further actual dissection or leakage was shown by the constant hæmoglobin level and the absence of leucocytosis. Osgood (1936) pointed out that the serum bilirubin may be increased in dissecting aneurysms, and a polymorphonuclear leucocytosis was found to be present in 80 per cent of acute dissections by Lawson (1952).

She had a persistent thymus $(7 \times 10 \times 1 \mathrm{~cm}$.). The significance, if any, of this cannot be assessed, but Kountz and Hempleman (1940) suggest endocrine disturbance as a possible factor in degeneration of the media. The left kidney, which was normal, took its blood supply from the false sac. Shennan (Case 16: 1934) reports only one such case in his series.

\section{Summary}

A case of dissecting aneurysm of the aorta is described. It had two unusual features, namely effective re-entry into both common iliac arteries, and a history that the patient's sister had died from the same cause.

We wish to thank Dr. T. E. Gumpert for his courtesy in furnishing details of the final illness; Dr. J. L. Edwards for the necropsy and histological reports; H.M. Coroner for North Leicestershire and Dr. A. Segerdal for details of the necropsy report on the patient's sister; and Dr. F. W. Boon of Rotherham for details of the patient's previous history and family history.

We are grateful to the Photographic Department at the Royal Hospital, Sheffield for the reproductions.

\section{References}

Kountz, W. B., and Hempleman, L. H. (1940). Amer. Heart J., 20, 599.

Lawson, C. W. (1952). M. D. Thesis (Sheffield University).

Osgood, E. E., Gourley, M. F., and Baker, R. L. (1936). Ann. intern. Med., 9, 1398.

Shennan, T. (1934). Medical Research Council Spec. Rep. Series 193.

Sinclair, R. J. G., Kitchin, A. H., and Turner, R. W. D. (1960). Quart. J. Med. N. S. 29, 19. 